\section{Sex education and AIDS}

SIR - It was slightly curious to find an editorial attack on the AIDS education policy of the New York City Board of Education made in the name of 'science and medicine' (Nature 359, 2; 1992). The board's statement that "abstinence is the most appropriate premarital protection against AIDS" is an incontrovertible medical truth. There is, however, another important fact, as your leading article rightly points out, which is that large numbers of young people engage in premarital sex. Therefore there clearly needs to be effective education also on the prevention of infection during intercourse. But it would not be scientifically correct to pretend that preventive measures are as safe as abstinence, and it would be irresponsible to withhold this important piece of information (which could save someone's life).

The aim of good education is to give people the facts and then let them make up their own minds. There is a certain irony in a scientific journal campaigning to prevent people being told clearly established facts.

\section{Denis R. Alexander}

Institute of Animal Physiology

\& Genetics Research,

Cambridge Research Station,

Babraham,

Cambridge CB2 4AT, UK

SIR - You are unfair to the New York City Board of Education. There is no scientific study proving that an educational programme emphasizing the use of condoms will protect a specified population against AIDS. In fact, in the school-child population being targeted in New York City, much medical common sense suggests that emphasis on the use of condoms will cause more AIDS than it will prevent.

First, as contraceptive experience has shown, condoms have at least a 2 per cent failure rate (as barrier to semen), because of breakage and slippage. Second, as students of teenage sexuality have shown, consistent use of condoms with consecutive coituses is extremely low in the teenage population. Third, emphasis on the use of condoms alone ignores the fact that AIDS is a disease spread by all body secretions and excretions, and not just by semen. Condoms do not protect against AIDS risks in open mouth-to-mouth kissing, bodybiting and much oral sex play.

On top of all these potential failures of the condom to protect against an infection with virtually 100 per cent mortality, the implicit acceptance by an educational institution of the legitimacy of its young teenage students having 'safe sex' in a society already made hypersexual by media stimulation can serve only to increase all kinds of sexual contact among the teenage population and therefore increase the spread of AIDS.

Saying no to too early sexual activity ought to be the chief topic of education against AIDS in such young school populations. It is the only 'safe sex'. The New York City Board of Education should be congratulated for showing such intelligent caring for its young wards. One would wish that Nature and New York's Mayor Dinkins would be as caring.

\section{Edward Stim}

Takashimadai, 4-4,

Nagamine Building, Apt 302.

Yokohama 221, Japan

\section{Anal sex and AIDS}

SIR - Per-Erik Åsard ${ }^{1}$ exhorts the AIDS scientific community to broadcast the dangers of anal sex, as practised by heterosexuals and bisexuals. It has been shown ${ }^{2}$ that the relative risk of human immunodeficiency virus (HIV) transmission from men to women is increased by a factor of 5.1 in anal compared with vaginal intercourse: that is, 46 per cent of women who practised anal sex with an HIV-infected man became HIV-positive.

Such appeals might be more effective if reinforced with mechanical rather than moral or statistical arguments. Here are some: the colonic and rectal mucosa has a barrier function that normally prevents overwhelming invasion by infective and toxic materials contained within the luminal contents. Exposure of rat colonic mucosa for 2-3 hours to human semen causes extensive damage to the rat mucosa as shown by histology, inhibition of fluid absorption and an increase in permeability to the normally impermeant high molecular weight probe, polyethylene glycol 4000 (ref. 3).

Human semen contains at least two components in sufficiently high concentrations to cause breakdown of the basement membrane that supports the colonic epithelial cell layer: collagenase, a component of seminal plasma, which hydrolyses the collagen present within the basement membrane, and spermine (concentration range in human semen $10-15 \mathrm{mM})$. Spermine permeates through the colonic mucosa and neutralizes glycoseaminoglycans within the interstitial matrix - this triggers the activation of endogenous collagenases which leads to loss of mucosal barrier function this allows seminal collagenase to penetrate the mucosa and hence to cause further damage and breakdown of the barrier function. Most of the mucosal damage caused by semen can be prevented by synthetic inhibitors of collagenase ${ }^{4}$. Thus it is apparent that the colorectal mucosa is particularly susceptible to biochemical as well as the normally assumed mechanical tauma consequent upon anal intercourse ${ }^{5}$.

\section{Richard J. Naftalin}

Biomedical Sciences Division,

Physiology Group,

King's College London,

Strand, London WC2R 2LS, UK

1. Åsard, P-E. Nature 359, 182 (1992)

2. European Study Group on Heterosexual Transmission of HIV Br. med. J. 304, 811 (1992).

3. Mendizabal, M. V. \& Naftalin, R. J. Clin. Sci. 82

277--282 (1992)

4. Clin. Sci. 83, 417-423 (1992).

5. Lorian, V. Lancet i, 1111 (1988).

\section{Belgian science}

SIR - As Alison Abbott says (Nature 358, 445; 1992), Belgium is divided both into two cultural communities, Frenchspeaking and Flemish-speaking, and into three regions Flanders, Wallonia and the capital Brussels. Each of these divisions serves a different administrative purpose, and basic science is administered at the community level. Thus the figure comparing the funds allocated by the Flemish and French-speaking divisions of the National Fund for Scientific Research (NFSR) to the populations of Flanders and Wallonia is misleading because it neglects the population of the Brussels region; the figures should instead have been compared with the French- and Flemish-speaking populations, including the one million citizens of Brussels. This is very important because 80 per cent of the capital's population is French-speaking.

Second, it was stated that a 'French speaker cannot apply for a grant from the Flemish NFSR nor vice versa'. In fact, the sole criterion determining which section of the NFSR is relevant is the language used by the university at which the applicant studied. At the moment, any Belgian is free to choose any university, irrespective of language, though the Flemish government is now trying to change this.

May I also point out that the Belgian state, which has its roots in the Middle Ages, was created in 1830 , not the "1830s". It seceded from the Netherlands after the Belgian revolution. It is therefore tendentious to qualify Belgium as "the product of recent history" obtained by "throwing together" Flanders and Wallonia and to limit its raison d'être to a "buffer between France and Germany".

\section{G. Berben}

Station de Chimie

et de Physique Agricoles,

B-5030 Gembloux, Belgium

NATURE · VOL 360 - 5 NOVEMBER 1992 